Asian Journal of Engineering and Applied Technology

ISSN 2249-068X Vol. 7 No. 1, 2018, pp.74-77

(C) The Research Publication, www.trp.org.in

\title{
Channel Allocation Scheme for Cellular Network Using Fuzzy Logic
}

\author{
Vikas Shinde \\ Department of Applied Mathematics, Madhav Institute of Technology and Science, Gwalior, Madhya Pradesh, India \\ E-Mail: v_p_shinde@ rediffmail.com
}

\begin{abstract}
This paper, deals fuzzy call admission control scheme to the requirement of quality of service. Quality of service is very critical issue in mobile communication because of dearth of spectrum resource and mobility of consumer and the main parameter is call dropping probable condition which shows the possibility of the extant relation being refusable during mobility. When the consumer's call suddenly abolished in the term of the connection is more troubling than being obstructed likely on a new call try. Performance of channel allocation scheme is evaluated, using fuzzy control in terms of call dropping probability and channel utilization
\end{abstract}

Keywords: Fuzzy rule, Call dropping probability, Traffic load

\section{INTRODUCTION}

A cellular system lies of a main switching system, likely mobile switching center and group of cells, every group with a fixed base station. Base stations directly communicate with all mobile stations around its half diameter of transmission. When the users move from one cell to another cell, handoff operation will come into the existence. Load network reallocate the channels, which is allocated to a network cells to balance and to avoid the overload of traffic. To handle the overload of traffic which varying from time to time through increases the capacity of system. It can be achieved by effective transferring channels from low loaded cells to heavy loaded cells.

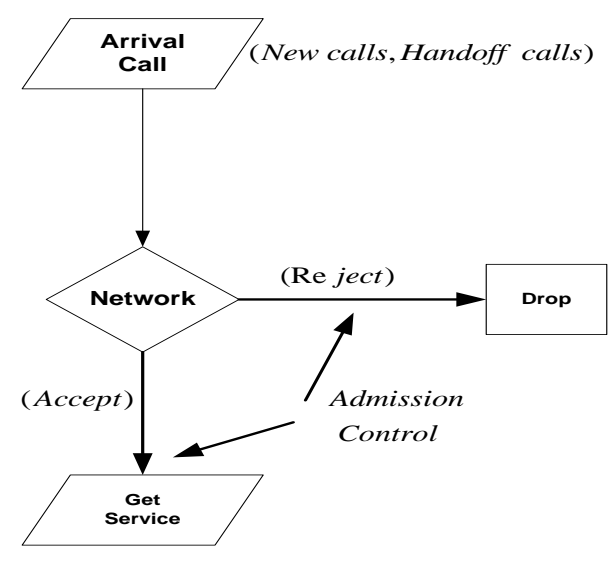

Fig. 1 Control systems for Call Admission

Recently fuzzy modeling is found to be very powerful tool for describe a real, complex and unknown process with nonlinear and time varying properties. Fuzzy rule is used for formulating fuzzy variables. A fuzzy rule is classified on cell to be poor, below average, average, above average. Collection of load information could be able to reflect its qualitative estimates of the current load on a cell. In a cellular system the arrival time of the calls may vary significantly as the call duration are uncertain and vague. Therefore fuzzy system can help us to obtain the best solution.

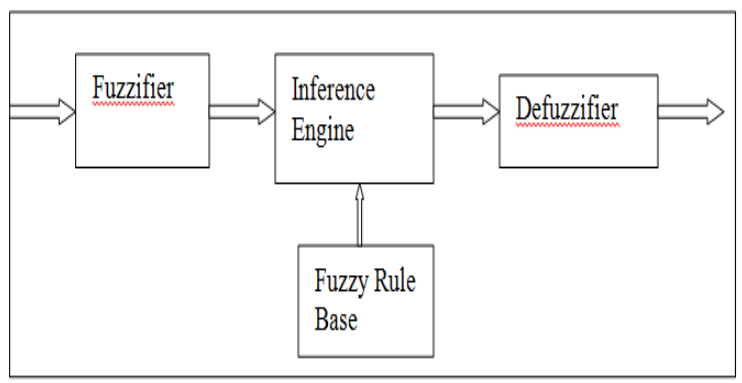

Fig. 2 Fuzzy Logic Controller

Several researches have been widely used fuzzy logic in different type of real world applications. Jiang and Rappaport [2] gave new channel assignment scheme which classified into fixed channel assignment, dynamic channel assignment and hybrid channel allocation. Ko and Cho [5] discussed adaptive handoff guard channel method using fuzzy logic. Dong and Lai [6] discussed conventional channel allocation approaches for cellular mobile with the classification of research and updation. Turksen et al [7] established fuzzy logic control rule for wireless cellular networks. Chong and Leung [8] proposed for fixed threshold values. Chen et al [9] proposed a fuzzy autoregressive scheme to provide an effective and efficient traffic management for achieving high-speed networks.

Wang \& Luoh [10] focused on defuzzification process when available computational capabilities are restricted by different parameters so in order to achieve a desired level of performance. Zhang and Lin [11] implemented and simulated an adaptive channel reservation scheme for wireless network. Wu et al [12] developed channel allocation algorithm for cellular networks. Wang and Shen [13] develop a policy to predicted the cell load and solve the channel borrowing scheme based on fuzzy logic. Ma et al [14] proposed fuzzy call admission control policy for getting requires quality of service. Sgore and Vergados [15] studied the detail survey of handoff prioritized channel assignment policy. Mallapur et al [16] considered buffer manager located at the base station using a fuzzy controller such as application priority, queue length and packet size for packet dropping in wireless cellular networks. Iancu 
[17] established one of the most accepted centroid defuzzification method for computing the defuzzification. Jain and Mittal [18] investigated call admission control scheme by exploiting the soft handoff coverage area of cellular system.

\section{CELLULAR SYSTEM USING FUZZY BASED}

Consider a cellular system, where numbers of cells are associated in hexagonal form and each served by the base station. Base station and the mobile host inform through the wireless links using channel. Every cell is allocated with a fixed group channels and common group of channels is reapplied by those identical cells. They are far from each other in order to avoid intervention. The intervention neighborhood of c, denoted by $I N(c)=\left\{c^{\prime} \mid \operatorname{dist}\left(c, c^{\prime}\right)<D_{\min }\right\}$,

where $D_{\min }=3 \sqrt{3 R}$ and $\mathrm{R}$ is half diameter of compact shape of different channels. If $\mathrm{N}_{\mathrm{i}}$ indicate the number of cells in the ring $\mathrm{i}$, and for the hexagonal geometry $N_{i}=1$ if $i=0$ and $N_{i}=6 i$ if $i>0$. The primary channels are denoted by $P_{i}(i=0,1,2, \ldots . . k-1)$ for the cells in $G_{i}$ and it is arranged in an ordered. Hence the cells in $G_{i}$ are primary cells of the channels in $P_{i}$ and secondary cells of the channels in $P_{j}(j \neq i)$ such group of cells construct the cell cluster. In this system, the arrival time of the call duration time and massage passing overhead among the cells are unclear and indecisive as discuss in figure 2.

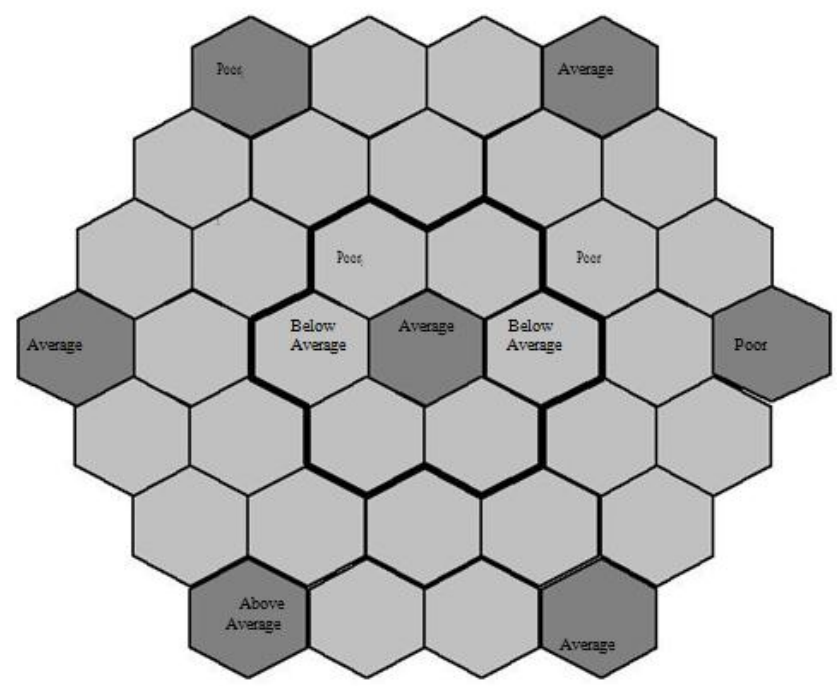

Fig. 3 Hexagonal Cellular Networks

\section{FUZZIFICATION MODULE}

Employ the available channel and traffic load as the input variables for the fuzzy sets. Fuzzification function is introduced for each input variable to express the allied measurement uncertainty. The grade of membership function reflects unfolds an ordering of the objects in fuzzy set $X$. The support of a fuzzy set $X$ is the crisp set of all $x \in$
$\Phi$ such that $\Phi_{x}>0$. i.e., $\operatorname{Sup}(X)=\left\{x \in \Phi, \Phi_{x}(x)>0\right\}$. There are operations of different fuzzy set. They are used for operations like as union, intersection and complement, Zadel [15] described the fuzzy operations are as follows

1. Complement: Let a fuzzy set $\mathrm{X}$ is denoted by $\bar{X}$ and the membership function of $\bar{X}$ is $1-\Phi_{X}(x), \forall x \in X$.

2. Intersection: Let fuzzy set $X \& Y$ is defined by $X \cap Y$ and the membership function of $X \cap Y$ is given by $X \cap Y=\min \left\{\Phi_{X}(x), \Phi_{Y}(x)\right\} \forall \mathrm{x} \in \mathrm{X}$.

3. Union: Let fuzzy set $\mathrm{X} \& \mathrm{Y}$ is defined by $X \cup Y$ and the membership function of $X \cup Y$ is given by $X \cup Y=$ $\max \left\{\Phi_{X}(x), \Phi_{Y}(x)\right\} \forall \mathrm{x} \in \mathrm{X}$.

The following relation in the interval $x \in\left[\mathrm{a}_{0}, \mathrm{a}_{5}\right]$ and $\mathrm{y} \in\left[\mathrm{b}_{0}, \mathrm{~b}_{2}\right]$, are mentioned as:

Poor $=\left\{\begin{array}{lr}1 & \text { when } x \leq a_{1} \\ \frac{\left(a_{1}-x\right)}{\left(a_{2}-a_{1}\right)} & \text { when } \quad a_{1}<x<a_{2} \\ 0 & \text { when } x \geq a_{2}\end{array}\right.$

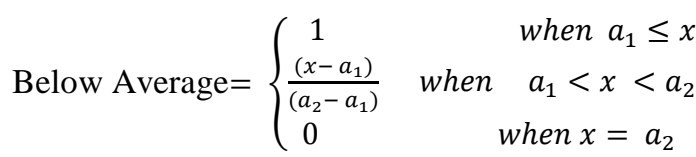

Average $=\left\{\begin{array}{l}0 \quad \text { when } a_{2} \leq x \geq a_{3} \\ \frac{\left(x-a_{2}\right)}{\left(a_{3}-a_{2}\right)} \text { when } a_{2}<x<a_{3} \\ 1\end{array}\right.$

Above Average $=\left\{\begin{array}{cc}0 & \text { when } a_{3} \leq x \geq a_{4} \\ \frac{\left(x-a_{3}\right)}{\left(a_{4}-a_{3}\right)} & \text { when } a_{3}<x<a_{4} \\ 1 & \text { when } x=a_{4}\end{array}\right.$

Low $=\left\{\begin{array}{cr}0 & \text { when } y \geq b_{1} \\ \frac{\left(y-b_{0}\right)}{\left(b_{1}-b_{0}\right)} & \text { when } \quad b_{0}<y<b_{1} \\ 1 & \text { when } y=b_{0}\end{array}\right.$

Medium $=\left\{\begin{array}{c}0 \quad \text { when either } y=b_{0} \text { or } y=b_{2} \\ \frac{\left(y-b_{0}\right)}{\left(b_{1}-b_{0}\right)} \text { when } b_{0}<y<b_{1} \\ \frac{\left(y-b_{1}\right)}{\left(b_{2}-b_{1}\right)} \quad \text { when } b_{1}<y<b_{2} \text {, when } y=b_{1}\end{array}\right.$

High $=\left\{\begin{array}{lr}0 & \text { when } y \geq b_{1} \\ \frac{\left(y-b_{1}\right)}{\left(b_{2}-b_{1}\right)} & \text { when } b_{1}<y<b_{2} \\ 1 & \text { when } y=b_{1}\end{array}\right.$

Consider the $X=\int_{\phi} \frac{\phi_{X}(X)}{x}$ and $Y=\int_{\phi} \frac{\phi_{y}(Y)}{y}$ where $\mathrm{X}$ is membership function and $\mathrm{x}$ is real input value for available channel and $\mathrm{Y}$ is membership function and $\mathrm{y}$ is real input value for traffic load. Let $a_{i}$ is lingual labels of available channel membership function for $0 \leq i \leq 5$ and $b_{j}$ is lingual labels of membership function for $0 \leq j \leq 2$. The status of $\mathrm{X}$ and $\mathrm{Y}$ are described for available channel and traffic load respectively.

\section{A. Fuzzy Rule Base}

Fuzzy Rule Base is depicted as group of fuzzy IF-THEN rule in which the preconditions and resultant blend lingual 
variables. Such group of fuzzy control indicates the simple input-output relation of the system. There are 20 fuzzy rules used in the table. Fuzzy controller can obtain the tuning number of guard channels according to the call drop rate and current number of the guard channels. The output parameter can be converted into a crisp value by the maximum membership inference method.

TABLE I FUZZY CONTROL RULES

\begin{tabular}{|c|c|c|c|}
\hline Rule & $\begin{array}{c}\text { IF } \\
\text { (call drop rate) }\end{array}$ & $\begin{array}{c}\text { AND (No. of } \\
\text { Guard } \\
\text { Channels) }\end{array}$ & $\begin{array}{c}\text { THEN (Tuning } \\
\text { No. } \\
\text { of Guard } \\
\text { Channels) }\end{array}$ \\
\hline R1 & Zero & Poor & Zero \\
\hline R2 & Zero & Below Average & Zero \\
\hline R3 & Zero & Average & Zero \\
\hline R4 & Zero & Above Average & Zero \\
\hline R5 & Poor & Poor & Zero \\
\hline R6 & Poor & Below Average & Zero \\
\hline R7 & Poor & Average & Below Average \\
\hline R8 & Poor & Above Average & Average \\
\hline R9 & Below Average & Poor & Below Average \\
\hline R10 & Below Average & Below Average & Poor \\
\hline R11 & Below Average & Average & Below Average \\
\hline R12 & Below Average & Above Average & Average \\
\hline R13 & Average & Poor & Below Average \\
\hline R14 & Average & Below Average & Below Average \\
\hline R15 & Average & Average & Average \\
\hline R16 & Average & Above Average & Average \\
\hline R17 & Above Average & Poor & Average \\
\hline R18 & Above Average & Below Average & Average \\
\hline R19 & Above Average & Average & Average \\
\hline R20 & Above Average & Above Average & Zero \\
\hline
\end{tabular}

In fig. 4-6 describe membership function for call dropping probability, guard channels and traffic load respectively.

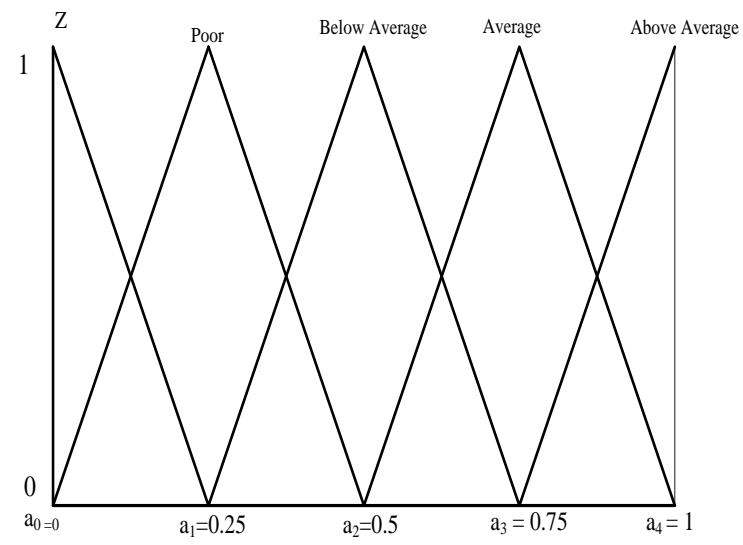

Fig. 4 Membership function for call dropping probability

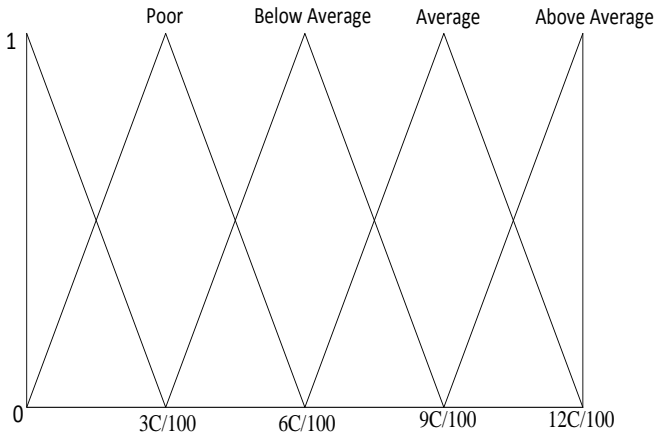

Fig. 5 Membership function for the guard channels

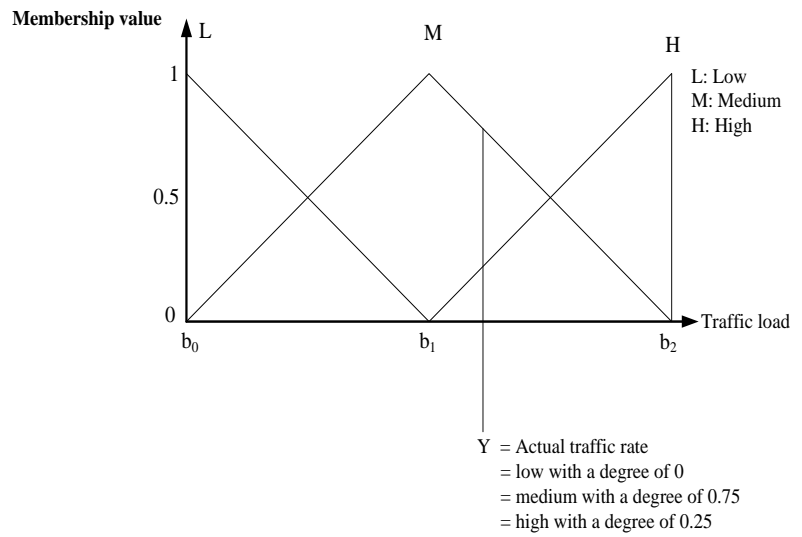

Fig. 6 Traffic Load

\section{B. Inference Engine}

Inference rule can be described in two ways. They are connectives by AND and ALSO may be interpreted as either union $(U)$ or intersection $(\cap)$ for different definition of fuzzy implication and denoted by $\max (\vee)-\min (\wedge)$ composition operators. Consider the rule $R_{i}$ with fuzzy implication $R_{c}$, the conclusion $C^{\prime}$ can be represented as the intersection of the individual conclusion of input linguistic state variables.

$$
\begin{aligned}
\phi_{c^{\prime}}(z) & =\bigcup_{x, y}\left\{\left[\phi_{X^{\prime}}(x) \cap \phi_{Y^{\prime}}(y)\right] \cap\left[\phi_{X_{i}}(x) \cap \phi_{Y_{i}}(y) \cap \phi_{Z_{i}}(z)\right]\right\} \\
& =\bigcup_{x}\left\{\left[\phi_{X^{\prime}}(x) \cap \phi_{X_{i}}(y) \cap \phi_{Z_{i}}(z)\right] \cap\left[\bigcup_{y}\left\{\phi_{Y^{\prime}}(y) \cap \phi_{Y_{i}}(y) \cap \phi_{Z_{i}}(z)\right]\right\}\right. \\
& =\bigcup_{x}\left\{\phi_{X^{\prime}}(x) \cap \phi_{X_{i}}(x) \cap \phi_{Z_{i}}(z) \cap \phi_{Y^{\prime}}{ }^{\circ} R_{c}\left(Y_{i} ; Z_{i}\right)(Z)\right\}
\end{aligned}
$$

Where $R_{c}\left(X_{i}, Y_{i}, Z_{i}\right)=\left(X_{i}\right.$ AND $\left.Y_{i}\right) \rightarrow Z_{i}$ i.e

$$
Z^{\prime}=\left(X^{\prime}, Y^{\prime}\right) \circ R_{c}\left(X_{i}, Y_{i}, Z_{i}\right)=\left[X^{\prime} \circ R_{c}\left(X_{i} ; Z_{i}\right)\right] \cap\left[Y^{\prime} \circ R_{c}\left(Y_{i} ; Z_{i}\right)\right]
$$

If inputs are fuzzy singletons, $X^{\prime}=x_{0}$ and $Y^{\prime}=y_{0}$ then the results $Z$, obtained by employing minimum operation rule $\mathrm{R}_{\mathrm{c}}$ and product operation rule $\mathrm{R}_{\mathrm{p}}$ respectively.

$$
\begin{aligned}
& R_{c}: \phi_{c^{\prime}}(z)=\bigcup_{i=1}^{n} \alpha_{i} \cap \phi_{c_{i}}(z)=\bigcup_{i=1}^{n}\left[\phi_{X_{i}}\left(x_{o}\right) \cap \phi_{Y_{i}}\left(y_{o}\right)\right] \cap \phi_{z_{i}}(z) \\
& R_{p}: \phi_{c^{\prime}}(z)=\bigcup_{i=1}^{n} \alpha_{i} \cdot \phi_{c_{i}}(z)=\bigcup_{i=1}^{n}\left[\phi_{X_{i}}\left(x_{o}\right) \cap \phi_{Y_{i}}\left(y_{o}\right)\right] \phi_{Z_{i}}(z)
\end{aligned}
$$

Where $\alpha_{i}$ is weight factor of the $\mathrm{i}^{\text {th }}$ rule which is measured by $i^{\text {th }}$ rule to the fuzzy control action. Four load actions, have been used which are poor, below average, average, 
above average. This paper consists of $4 \times 3=12$ possible rules. The possible 12 combination between available channel and traffic load is described in fig. 3 .

TABLE II FUZZY CONTROL RULES FOR CHANNEL

\begin{tabular}{|l|l|l|l|}
\hline $\begin{array}{l}\text { Load } \\
\text { Availabłd } \\
\text { channel }\end{array}$ & Low & Moderate & \multicolumn{1}{c|}{ High } \\
\hline Poor & $\begin{array}{l}\text { (1)Positive } \\
\text { Small }\end{array}$ & $\begin{array}{l}\text { (2)Positive } \\
\text { Medium }\end{array}$ & $\begin{array}{l}\text { (3)Stable } \\
\text { Zero }\end{array}$ \\
\hline $\begin{array}{l}\text { Below } \\
\text { Average }\end{array}$ & $\begin{array}{l}\text { (4)Positive } \\
\text { Small }\end{array}$ & $\begin{array}{l}\text { (5)Positive } \\
\text { Medium }\end{array}$ & $\begin{array}{l}\text { (6)Positive } \\
\text { Medium }\end{array}$ \\
\hline Average & (7)Positive & (8)Positive & (9)Positive \\
& Medium & Large & Large \\
\hline $\begin{array}{l}\text { Above } \\
\text { Average }\end{array}$ & (10)Stable & $\begin{array}{l}\text { (11)Positive } \\
\text { Zero }\end{array}$ & $\begin{array}{l}\text { (12)Positive } \\
\text { Large }\end{array}$ \\
\hline
\end{tabular}

\section{Defuzzification}

The process of defuzzification helps to control the problems in real life. It actually helps to control the action. Centroid technique for defuzzification is considered in obtaining a centre of gravity (COG) of the aggregated fuzzy set. A realistic estimate can be carried out by evaluating it over a sample of points.

$$
\begin{gathered}
C O G=\frac{(0+10+20) \times 0.2+(30+40+50+60) \times 0.35+(70+80+90+100) \times 0.5}{0.2+0.2+0.2+0.35+0.35+0.35+0.35+0.5+0.5+0.5+0.5} \\
=\frac{6+63+170}{0.6+1.4+2}=\frac{239}{4}=59.75
\end{gathered}
$$

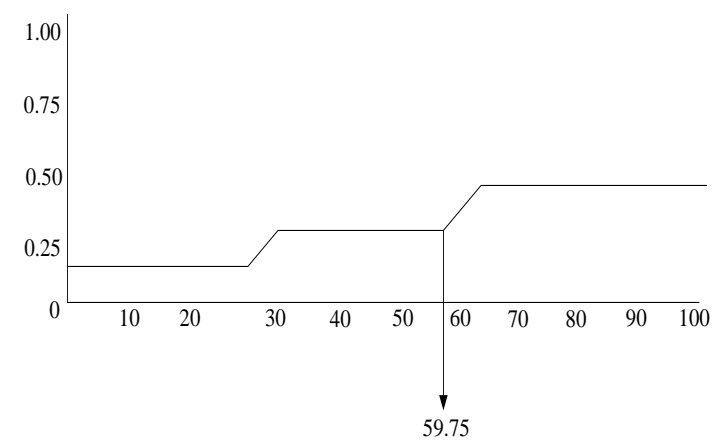

Fig. 7 Centre of Gravity

\section{CONCLUSION}

The present investigation highlights the call admission control scheme based on fuzzy logic. It believes that a fuzzy scheme is more capable to provide better control and management of cellular networks than the probabilistic approaches. Centroid defuzzification method provides a good performance. It also gives robust performance of the cellular networks like dropping rate, channel acquisition delay and messages complexity.

\section{REFERENCES}

[1] L. A. Zadel, "Fuzzy Algorithm, Information and Control", pp. 94$102,1968$.

[2] H. Jiang and S. S. Rappaport, "CBWL a New Channel Assignment and Sharing Method for Cellular Communication Systems", IEEE Transactions on Vehicular Technology, pp. 313-322, 1994.

[3] T. J. Ross, "Fuzzy Logic with Engineering Application", New York, Mc-Graw-Hill, 1995.

[4] T. S. Rappaport, "Wireless Communication Principles and Practice", New York, Prentice-Hall, 1996.

[5] Y. Ko and C. Cho, "Adaptive Handoff Guard Channel Allocation Scheme Using Fuzzy Logic in Personal Communications Series", in Proc. of the IEEE ICUPC Conference, pp. 239-243, 1997.

[6] X. Dong and T. H. Lai, "Distributed Dynamic-Carrier Allocations in Mobile Cellular Networks Search vs Update", IEEE Distributed Computing Systems, pp. 108-115, 1997.

[7] I. B. Turksen, M. R. Emami and A. A. Goldenberg, "Development of a Systematic Methodology of Fuzzy Logic Modeling", IEEE Transactions on Fuzzy Systems, pp. 346-360, 1998.

[8] P. H. J. Chong and C. A. Leung, "A New Channel Borrowing Scheme with Interference Information for Cellular Systems", IEEE Transactions on Vehicular Technology, pp.1426-1438, 1999.

[9] B.S. Chen, S. C. Peng and K. C. Wang, "Traffic Modeling Prediction and Congestion Control for High-Speed Networks: A Fuzzy AR Approach", IEEE Transactions on Fuzzy Systems, Vol. 8, No. 5, pp. 491-508, 2000

[10] Wen-June Wang and Leh Luoh, "Simple Computation for the Defuzzification of Centre of Sum and Center of Gravity", Journal of Intelligent and Fuzzy Systems, Vol. 9, pp. 53-59, 2000.

[11] Y. Zhang and D. Lin, "An Adaptive Algorithm for Call Admission Control in Wireless Network", in Proc. of the IEEE GLDBE Com. Conference, pp. 3628-3632, 2001.

[12] E. H. K. Wu, M. H. Jin, and J. T. Horng, "A Channel Allocation Algorithm for Large Scale Cellular Networks", IEEE Parallel and Distributed Systems, pp. 465-470, 2002.

[13] Y. T. Wang, and J. P. Shen, "A Dynamic Channel Borrowing Approach with Fuzzy Logic Control in Distributed Cellular Networks", Journal of Simulation Modeling Practice and Theory, Vol. 12, pp. 287-303, 2004.

[14] Y. Ma, X. Hu, Y. Zjang and Y. Shi, "Intelligent Call Admission Control using Fuzzy Logic in Wireless Networks", in Proc. of the American Control Conference, Portland, USA, pp. 3981-3985, 2005.

[15] A. Sgore, and D. Vergados, "Handoff Prioritization and Decision Scheme in Wireless Cellular Network: A Survey", IEEE Communications Survey and Tutorials, Vol. 11, No. 4, pp. 57-77, 2009.

[16] J. D. Mallapur, S. S. Mavi and D. H. Rao, "Fuzzy-Based Approach for Packet Dropping in Wireless Networks", International journal of Advanced Networking and Applications, Vol. 1, No. 5, pp. 301-306, 2010.

[17] Ion Iancu, "Fuzzy Logic - Controls, Concepts, Theories and Applications, Edit: Elmer Dadios", Published by In-tech, Chapter-16, 325-350, 2012.

[18] M. Jain, and R. Mittal, "Call Admission Control for Soft Handoff Coverage in CDMA Cellular System", International Journal of Wireless Information Networks, Vol. 22, pp. 53-66, 2015. 